\title{
Technical Efficiency of Tilapia Production in Malawi And China: Application of Stochastic Frontier Production Approach
}

\section{Francis Phiri*1,3 and Xinhua Yuan ${ }^{1,2}$}

${ }^{1}$ Wuxi Fisheries College, Nanjing Agricultural University, Wuxi, Jiangsu, P.R. China

${ }^{2}$ Freshwater Fisheries Research Centre, Chinese Academy of Fishery Sciences, Shanshui East Road No. 9, Wuxi, Jiangsu, P.R. China

${ }^{3}$ Department of Fisheries, National Aquaculture Centre, PO Box 44, Domasi, Zomba, Malawi

\begin{abstract}
In the present study, stochastic frontier production function was applied to estimate both the technical efficiency scores and determinants of inefficiency for 20 tilapia farms apiece in Malawi and China. The study used the CobbDouglas model in which efficiency estimates showed that tilapia farmers in Malawi were more technically inefficient than farmers in China, with mean efficiency scores of $47 \%$ and $91 \%$ respectively. With exception of aquaculture experience, all the inefficiency determinants were positive for Malawian farms even though none of the coefficients was significant. For Chinese tilapia farmers, age (significant), household size and education had negative signs except aquaculture experience. The Malawian tilapia industry need technology innovations in order to reduce the existing $53 \%$ yield gap, which can ideally be introduction or development of new strains of superior quality, enhanced use of all-male tilapia, improvement in both nursing and grow-out technologies as well as use of quality fish feed.
\end{abstract}

Keywords: Stochastic frontier production; Technical efficiency; Tilapia; Elasticity; Cobb Douglas

\section{Introduction}

\section{Background information}

Global fish production from both the capture fisheries and aquaculture is not keeping pace with its growing demand from a growing population, and Malawi and China are no exceptions. Malawi's annual per capita fish consumption was $8.12 \mathrm{~kg}$ in 2014 [1], which is short of the global and China's per capita of $19.7 \mathrm{~kg}$ and $37.9 \mathrm{~kg}$ respectively [2]. This is clear indication that there is great shortage of fish production in Malawi. With human consumption of farmed species exceeding that of capture fisheries for the first time in 2014, FAO [2] reports that aquaculture is expected to further increase its share and provide 57 percent of fish for human consumption in 2025. Increased aquaculture production can help to meet the increased domestic demand for fish and also to meet protein availability. However, between 2010 and 2014, annual aquaculture production in Malawi has slowly increased from 2346 to 4119.48 metric tons [3]. This slow growth is attributed to a number of factors including poor quality fingerlings from a genetically depreciated strain, poor quality feed, and use of archaic technologies in the production system. These high-risk challenges have resulted in high fish mortality and low growth, which, adversely affected yield as well as production cost. Use of archaic technologies have brought technical inefficiency which has a great effect in productivity of aquaculture establishments. Thus, focussing on a mere increase in number of fish farmers and their establishments may not necessarily assure increased supply of fish products. However, the farms must be able to operate at their fullest production potential. Production efficiency-oriented studies for fish farming have been very limited in Malawi i.e., IAA adoption by Mussa [4], hence the concessional genesis of this study to estimate the level of technical efficiency (TE) of tilapia farms and evaluate the factors affecting farm efficiency. As stated earlier, most small-scale tilapia farmers use extensive to semi-intensive technologies, hence have low per unit productivity ranging from 500 to $2316 \mathrm{~kg}$ per ha [5]. The culture period is usually 6 months, and farmers have two crops per year as the average seasonal temperature according to Malawi Government [6] is $31^{\circ} \mathrm{C}$ in summer and $22^{\circ} \mathrm{C}$ in winter.

\section{Conceptual framework}

As reported by Fare et al., [7] and Farrell [8] technical efficiency is a major component of productivity which itself is a measure of farm performance. Ideally, technical efficiency indicates whether a farm uses the best available technology. It reflects the ability of a farm to obtain maximum output from a given set of inputs [9]. A technically efficient farm operates on the production frontier. A technically inefficient farm, i.e., one that operates below the frontier can achieve optimum efficiency either by increasing output with the same input-bundle or using less input to produce the same output. The closer a farm gets to the frontier, the more technically efficient it becomes.

Despite a system utilising all required inputs, there are many factors that can potentially bring inefficiency in aquaculture production. An individual's education affects his/her ability to allocate inputs costeffectively, farmer's age, years in practice and exposure to technical information through trainings and interaction with extension workers are some of the core factors that affect a farm's technical efficiency through poor allocation of resources, and application of technological acumen.

Total tilapia production in Malawi and China is characteristically dependant on a number of input factors. Among the main factors are feed, seed, labour, manure/fertilisers and drugs. In general, feed is given twice a day in the morning and evening. Farmers also use fertilisers, especially animal manure to enhance primary productivity in their ponds to reduce feed application, as tilapia exhibit ontogenic feeding behaviour. In terms of seed, Malawian farmers use Oreochromis shiranus, which is an indigenous species and like all tilapia, the fish exhibit a number of drawbacks including early sexual maturity and unwanted reproduction [10-12] while for Chinese farmers, GIFT strain and the hybrid $\mathrm{Ni}$ ao (Oreochromis niloticus $\times$ Oreochromis aureus) are

*Corresponding author: Francis Phiri, Department of Fisheries, National Aquaculture Centre, P.O. Box 44, Domasi, Zomba, Malawi, Tel: +265888358737; E-mail: phraphiri@yahoo.co.uk

Received March 15, 2018; Accepted May 07, 2018; Published May 12, 2018

Citation: Phiri F, Yuan X (2018) Technical Efficiency of Tilapia Production in Malaw And China: Application of Stochastic Frontier Production Approach. J Aquac Res Development 9: 532. doi: 10.4172/2155-9546.1000532

Copyright: @ 2018 Phiri F, et al. This is an open-access article distributed unde the terms of the Creative Commons Attribution License, which permits unrestricted use, distribution, and reproduction in any medium, provided the original author and source are credited. 
the two commonly cultured species [13], which have superior growth rate. As Govender [14] reports, labour is a measure of the work done by human beings. It is conventionally contrasted with such other factors of production as land and capital. Ideally, minimal labour is required to operate fish ponds, as adding more workers is not likely going to increase fish production. In the present study, the output variable was in the form of amount of tilapia in kgs produced per production establishment.

It is a general observation that resources in the fish farming industry in Malawi are being inefficiently utilized. The absence of quantitative research on technical efficiency is surprising; as there is a greater prospect of the tilapia sector improving its efficiency if determinants of technical inefficiency are isolated and estimated. As reported earlier on, there is little literature about efficiency estimates for fish farming in Malawi. Therefore, this study is expected to provide meaningful insights into the level of farm-specific technical efficiency along with factors affecting inefficiency. The present study focuses on smallscale semi commercial tilapia farmers in Malawi and compares their efficiency with tilapia producers in China. The study uses stochastic production frontier function by specifying the Cobb-Douglas model for technical inefficiency effects to obtain the empirical results hence determines the technical efficiency estimates and identify determinants of technical inefficiency for the farms.

\section{Research Methodology}

\section{Study areas}

This study was conducted in Malawi and China. Malawi has three seasons, and viz: the dry season running from August to October, the rainy season which stretches from November to April and the cool season which runs from May to July. The country's temperature and rainfall is mainly influenced by the lake and altitude, varying from $37 \mathrm{~m}$ in the Shire Valley Region, to $3050 \mathrm{~m}$ in the Mulanje Mountain area. Annual rainfall is between $635 \mathrm{~mm}$ and $3050 \mathrm{~mm}$. Although rainfall varies, most parts of the country receive enough rain for dry land farming (except during periods of drought). The study was rather conducted in all the three administrative regions of: North, Centre and South. Farmers were sampled from the following districts: - Nkhatabay, Mzimba and Rumphi in the North, Lilongwe and Mchinji in the Centre and Zomba, Mangochi, Thyolo, Mulanje and Chikwawa in the South.

In China, the study was conducted in Guangxi Province. The Province is located in a sub-tropical region, where tilapia can be cultured and supplied all year round due to warm climate and rich rainfall [13]. Other advantages for tilapia culture in the province include: relatively long history of tilapia culture, good tilapia selection programs, well-developed large-scale tilapia hatcheries, well-trained researchers and extension workers [15]. The province also has tilapia processing factories that have been authorized by Hazard analysis of Critical Control Points (HACCP) and acquired accreditation for producing export quality products intended for the European Union (EU), USA and Japan markets, and this has also fostered the further expansion of tilapia culture in the province [15]. In 2014, the tilapia farming area in Guangxi comprised about 23,000 ha [16]. According to the China Fisheries Yearbook 2013-2014, tilapia production in Guangxi has increased by $10 \%$ on average between 2004 and 2013 against China's $7.16 \%$, while contributing an averaged $16 \%$ to the total tilapia output.

\section{Data collection}

To generate economics data for Malawi, the study targeted 20 small- scale semi commercial fish farmers located in all the three regions of the country. The farmers were interviewed between December 2016 and February 2017 through administration of a structured questionnaire. Data and information collected include: sex, age, gender, marital status, education level, pond sizes, inputs (seed, feed, manure, drugs and labour), number of ponds owned, production level and pricing (farm gate prices, factors affecting pricing). Oral informed consent was obtained from each study participant before commencement of the interview, as the enumerator briefly explained the purpose of the study, the risks and benefits of participation in the study, and conditions of confidentiality. As reported by Ahmed et al. [17], participatory, qualitative, and quantitative methods were combined in the primary data collection.

For China, secondary data from Guangxi Province, which was collected in 2014 was used. A random sampling survey was employed to identify the target farmers and data was collected through administration of structured questionnaires by a team of enumerators. Data exploration was therefore done to screen and organize the secondary data for identification of 20 small scale tilapia farmers to be part of the present study. Among the factors considered in the data exploration were identifying those famers that met the study criteria by having all above-mentioned study parameters for inputs, output and marketing data. However, Chinese farmers did not have data on manure for pond fertilisation, but inversely they had electricity as an input of production.

\section{Data analysis}

For better comparative analysis of the two production systems, efficiency estimates [8] rather than effectiveness measures were used. Stochastic Production Frontier (SPF) approach [18-20] is one of the efficiency estimate models that have been employed in recent studies [21-25] have employed the FRONTIER 4.1 software, and used [26], to simultaneously estimate the parameters of the SPF and the TE models. The stochastic production frontier and technical inefficiency models have been widely used in determining farm-level efficiency in developing countries' agriculture since the publication of a seminal article of Farrell [8] on efficiency measurement and subsequent development of several approaches to efficiency and productivity measurement. The most basic method of TE is to map a production frontier (statistically or non-statistically, parametrically or nonparametrically), find the locus of maximum output levels associated with given input levels and estimate farm-specific TE as a deviation from the fitted frontier.

Among different major approaches followed to measure and estimate efficiency, the stochastic production frontier (SPF) approach involving econometric estimation of parametric function [18-20] and nonparametric programming, known as data envelopment analysis (DEA) [27], are the most popular. The stochastic frontier is considered more appropriate for assessing TE in developing countries' agriculture production, where the data are often heavily influenced by measurement errors and other stochastic factors such as weather conditions, diseases, etc. [7,9,22-23,28-30]. Several recent studies have applied stochastic frontier technique for determining efficiency in aquaculture in the developing Asian countries [21,23-25,31-35] and African countries [4,36-40].

There are two approaches to analyse determinants of TE or inefficiency. A number of authors first estimated stochastic frontiers to predict firm-level efficiencies and then regressed these predicted efficiencies upon farm-specific variables (such as managerial experience, ownership characteristics and production conditions) in 
an attempt to explain variations in output between firms in an industry $[41,42]$. This is usually referred to as a two-stage procedure. Several economists have however criticised this procedure [43-45] arguing that the socioeconomic variables should be incorporated directly into the estimation of production frontier model because such variables may have a direct influence on the production efficiency. To overcome inconsistencies in the assumptions regarding the independence of inefficiency effects in this two-stage estimation procedure, Kumbhakar et al. [44] and Reifschneider and Stevenson [45] proposed a singlestage stochastic frontier model in which the inefficiency effects $\left(u_{i}\right)$ are expressed as an explicit function of a vector of farm specific variables and a random error.

Nevertheless, in spite of the criticisms, many studies have used two-stage approach; Simar and Wilson [46] have mentioned of about 800 published articles and working papers that have followed two-stage approach for measuring efficiency. This study however, employed the single-stage stochastic frontier model in estimating farm TE and its associated inefficiency factors. The parameters were estimated using the following formulas and functions. The SPF with two error terms was modelled as:

$$
Y_{i}=f\left(X_{i} \beta\right) \exp \left(V_{i}-U_{i}\right)
$$

Where $Y_{i}$ is the production of the $\mathrm{i}$-th farm $(i=1,2,3 \ldots \ldots \ldots \ldots . . . \mathrm{n})$, $X_{i}$ is a $(1 \mathrm{x} \mathrm{k})$ vector of functions of input quantities applied by the $\mathrm{i}$-th farm; $\beta$ is a ( $\mathrm{kx} 1)$ vector of unknown parameters to be estimated, $V_{i} s$ are random variables assumed to be independently and identically distributed as $N\left(O, \delta^{2}\right)$ and independent of $U_{i}$ and the $U_{i}$ are nonnegative random variables, associated with technical inefficiency in production assumed to be independently and identically distributed as truncation (at zero) with mean $Z_{i} \delta$ and variance $\sigma_{u}^{2}\left(\mathrm{U} \sim\left|\mathrm{N}\left(\mathrm{Z}_{\mathrm{i}} \delta, \sigma_{2}^{2}\right)\right|\right)$; $Z_{i}$ is a $(\mathrm{m} \mathrm{x} 1)$ vector of farm specific variables associated with technical inefficiency, and $\delta$ is a $(\mathrm{m} \times 1)$ vector of unknown parameters to be estimated [47].

Following [26], the technical inefficiency effects $U_{i}$ in equation (1) was expressed as:

$$
U_{i}=Z_{i} \delta+W_{i}
$$

Where $W_{i}$ are random variables defined by the truncation of the normal distribution with zero mean and variance $\sigma^{2}{ }_{u}$ such that the point of truncation is at $Z_{i} \delta$, i.e. $W_{i} \geq-Z_{i} \delta$.

The maximum likelihood estimates (MLE) of the parameters of the model defined in equations ( 1 ) and (2) were estimated using the Frontier 4.1 package [48]. The efficiencies are estimated using a predictor that is based on the conditional expectation of $\exp (-U)[48,49]$. In the process, the variance parameters $\sigma_{u}^{2}$ and $\sigma_{v}^{2}$ are expressed in terms of the parameterization:

$$
\sigma^{2}=\left(\sigma_{u}^{2}+\sigma^{2}{ }_{v}\right) \ldots \ldots \ldots \ldots \ldots
$$

and

$$
\gamma=\left(\sigma_{u}^{2} / \sigma^{2}\right)
$$

The value of $\gamma$ (Equation 4) ranges from 0 to 1, with values close to 1 indicating that random component of the inefficiency effects makes a significant contribution to the analysis of the production system [50].

\section{Model Specification}

A number of functional forms exist, that have been developed to measure the physical relationship between inputs and output. The most common form in practice is the Cobb-Douglas (CD). The stochastic production frontier for tilapia farming in Malawi and China was therefore estimated using the Cobb-Douglas functional form as specified below:

$$
\operatorname{In} Y_{i}=\beta_{0}+\sum_{k=1}^{n} \beta_{k} \operatorname{In} X_{K i}+V_{i}-U_{i} \ldots \ldots \ldots \ldots . . .
$$

Where subscript $i$ refers to the $i$ th observation in the sample ( $i=$ $1,2,3 \ldots .20) ; \ln$ represents the natural logarithm; $\beta_{o^{\prime}} \beta_{k}$ are parameters to be estimated. $Y$ is observed farming system output (expressed in $\mathrm{kg}$ ). $X$ represents the total number of tilapia fingerlings stocked, $X_{2}$ is the total amount of feed used in the production cycle (expressed in $\mathrm{kg}$ ), $X_{3}$ is the total cost of manure and fertilizer applied (expressed in USD), $X_{4}$ is the total value of drugs (including lime) applied by the farmer (expressed in USD), $X_{5}$ is the total cost of electricity used (expressed in USD), $X_{6}$ is the total value of labour used during the production cycle (expressed in USD) and $V_{i}$ and $U_{i}$ are noise and inefficiency respectively.

\section{Results}

\section{Sample characteristics}

Table 1 presents the measurement of output and input variables in the SPF and technical inefficiency model, while Table 2 gives the summary statistics of the relevant variables for tilapia farmers in the two countries. The table reveals that considerable variation exists among the farms in terms of production practices and the socio-economic attainments of the farmers within their respective countries. Mean output from Malawian farms was $524.51 \mathrm{~kg}$, ranging from a minimum of $120.23 \mathrm{~kg}$ to as high as $2184.00 \mathrm{~kg}$. Main inputs of feed, labour and seed cost were USD348.86, USD197.46 and USD89.69 respectively. Cost of drugs and manure were USD26.15 and USD17.17.304. For inefficiency factors, age averaged 53.95 years which was within a range of 84 and 31, while households had an average of 5.5 people, with most of the farmers having gone beyond high school education (2.35), apart from having 4.8 years of experience. Pond sizes were averaged at $1082.95 \mathrm{~m}^{2}$. Chinese farmers registered a mean output of $976.76 \mathrm{~kg}$ with a minimum of $722 \mathrm{~kg}$ and a maximum of $1190.48 \mathrm{~kg}$ per mu. Seed input was 2039.33, while feed used was $1334.11 \mathrm{~kg}$. Other inputs were drugs, electricity and labour with costs of USD12.80, USD21.84 and

\begin{tabular}{|c|c|c|}
\hline Variables & Description & Unit \\
\hline $\mathrm{Y}$ & Total tilapia production for the sample farms & $\mathrm{Kg}$ \\
\hline \multicolumn{3}{|c|}{ Variables in the production frontier } \\
\hline$x_{s}$ & Number of fingerling stocked in ponds & -- \\
\hline$X_{F}$ & Amount of feed used & $\mathrm{Kg}$ \\
\hline $\mathrm{X}_{\mathrm{M}}$ & Cost of manure applied & $\mathrm{USD}^{\mathrm{a}}$ \\
\hline$X_{D}$ & Cost of drugs applied & $\mathrm{USD}^{\mathrm{a}}$ \\
\hline$X_{E}$ & Cost of electricity used & USD $^{\mathrm{a}}$ \\
\hline$X_{L}$ & Cost of labour employed & $\mathrm{USD}^{\mathrm{a}}$ \\
\hline \multicolumn{3}{|c|}{ Variables in the inefficiency function } \\
\hline$Z_{\text {AGE }}$ & Age of tilapia farmers & Years \\
\hline$Z_{H H S}$ & Household size of farmers & Years \\
\hline$Z_{E L}$ & $\begin{array}{c}\text { Education level (1= University, } 2=\text { College, } 3= \\
\text { High, } 4=\text { Primary, } 5=\text { None })\end{array}$ & \\
\hline$Z_{A E}$ & Experience of tilapia farmers in aquaculture & Years \\
\hline$Z_{\mathrm{PS}}$ & Pond size & $\mathrm{M}^{2}$ \\
\hline $\mathrm{D} 1=\mathrm{K} 72$ & $6.67 ¥$ & \\
\hline
\end{tabular}
USD65.84 respectively. Technical inefficiency factors included age 47.65 years, household size averaged 1.85 people while education was at 3.60 with most farmers attaining primary education, and the farmers had mean experience of 9.55 years.

Table 1: Measurement of output and input variables in the SFPF and technical inefficiency model for tilapia farmers in Malawi and China. 
Citation: Phiri F, Yuan X (2018) Technical Efficiency of Tilapia Production in Malawi And China: Application of Stochastic Frontier Production Approach. J Aquac Res Development 9: 532. doi: 10.4172/2155-9546.1000532

Page 4 of 7

\section{Hypotheses testing}

The sigma squared $\left(\sigma^{2}\right)$ which is an indication of goodness of fit was statistically significant at $5 \%$ level (Table 3 ), showing the goodness of fit of the survey data from both countries with the model used and the correctness of the specified coefficients. To test the null hypothesis that there was no significant technical inefficiency hence observed variations in TE estimates were simply random or systematic $\left(\mathrm{H}_{0}=\right.$ 0 ), an estimated $\gamma$ parameter, which measures the variability of the two sources of error was statistically significant at $1 \%$, hence it was suggested that $99 \%$ of the total variation of total production were related to inefficient error term and $1 \%$ of the total variations attributed to stochastic random errors. This implies that the variation of the total production among the different tilapia farms in both countries was due to the differences in their production inefficiencies.

\section{Technical efficiency estimates and inefficiency factors}

Table 3 presents respective individual coefficients and the corresponding t-ratios for the stochastic production frontiers for the two farming categories. For Malawian farms, all the elasticity of production except for the labour coefficient have the expected a priori positive sign. For Chinese farms, all the production coefficients have positive contribution towards the production frontier.

In the present study, results of technical inefficiency estimates show that all determinants of inefficiency except aquaculture experience had positive signs for the Malawian farms even though none of the coefficients was significant. For Chinese tilapia farmers, age (significant), household size and education had negative signs except aquaculture experience which was positive.

\section{Technical efficiency distribution}

For a clearer indication and understanding of the distribution of technical efficiencies among tilapia farmers in the two countries, the frequency distributions of the estimated efficiencies are plotted in Figures 1 and 2. The results show that $65 \%$ of tilapia farmers in Malawi

\begin{tabular}{|c|c|c|c|c|}
\hline Name of variables & Mean & Max & Min & SD \\
\hline \multicolumn{5}{|c|}{ Malawi } \\
\hline Expected Yield (kg) & 524.51 & 2184.00 & 120.23 & 572.34 \\
\hline Seed & 6773.70 & 21000.00 & 1452.00 & 4422.83 \\
\hline Feed $(\mathrm{kg})$ & 425.00 & 900.00 & 150.00 & 200.82 \\
\hline Manure cost (USD) & 17.17 & 41.41 & 3.04 & 9.49 \\
\hline Drugs/lime cost (USD) & 26.15 & 71.78 & 9.13 & 17.26 \\
\hline Labour (USD) & 197.46 & 628.06 & 45.63 & 155.68 \\
\hline Age (years) & 52.95 & 84.00 & 31.00 & 14.71 \\
\hline HH size & 5.50 & 8.00 & 4.00 & 1.36 \\
\hline Education & 2.35 & 4.00 & 1.00 & 1.14 \\
\hline Experience (years) & 4.80 & 13.00 & 1.00 & 3.27 \\
\hline Pond size $\left(\mathrm{m}^{2}\right)$ & 1082.95 & 3500.00 & 400.00 & 683.62 \\
\hline \multicolumn{5}{|c|}{ China } \\
\hline Expected Yield (kg) & 976.76 & 1190.48 & 722.22 & 116.75 \\
\hline Seed & 2039.33 & 2800.00 & 1100.00 & 512.89 \\
\hline Feed $(\mathrm{kg})$ & 1334.11 & 1771.48 & 922.65 & 231.08 \\
\hline Electricity (USD) & 12.80 & 20.61 & 5.00 & 3.38 \\
\hline Drugs/lime (USD) & 21.84 & 74.96 & 3.75 & 16.16 \\
\hline Labour cost (USD) & 65.84 & 110.05 & 22.63 & 27.88 \\
\hline Age (years) & 47.65 & 70.00 & 36.00 & 7.55 \\
\hline $\mathrm{HH}$ size & 1.85 & 5.00 & 1.00 & 1.04 \\
\hline Education & 3.60 & 4.00 & 2.00 & 0.60 \\
\hline Experience (years) & 9.55 & 22.00 & 1.00 & 5.74 \\
\hline
\end{tabular}

Table 2: Summary statistics of the variables.

\begin{tabular}{|c|c|c|c|c|c|}
\hline \multirow{2}{*}{ Variable } & \multirow{2}{*}{ Parameter } & \multicolumn{2}{|c|}{ Malawi } & \multicolumn{2}{|c|}{ China } \\
\hline & & coefficient & t-ratio & coefficient & t-ratio \\
\hline \multicolumn{6}{|c|}{ Production frontier } \\
\hline Constant & $\beta_{0}$ & -1.174 & -0.648 & $3.227^{* * *}$ & 3.480 \\
\hline$x_{s}$ & $\beta_{1}$ & 0.065 & 0.249 & 0.015 & 0.135 \\
\hline$X_{F}$ & $\beta_{2}$ & $1.403^{* * *}$ & 4.279 & $0.434^{* * *}$ & 3.031 \\
\hline$X_{M}$ & $\beta_{3}$ & 0.188 & 1.468 & -- & -- \\
\hline$X_{D}$ & $\beta_{4}$ & 0.017 & 0.061 & $0.144^{\star * *}$ & 3.437 \\
\hline$X_{E}$ & $\beta_{5}$ & -- & -- & $0.035^{\star *}$ & 2.430 \\
\hline$X_{L}$ & $\mathrm{~B}_{6}$ & -0.311 & -1.574 & 0.010 & 0.265 \\
\hline \multicolumn{6}{|c|}{ Inefficiency function } \\
\hline Constant & $\delta_{0}$ & $0.857^{*}$ & 1.855 & $0.891^{* * *}$ & 3.414 \\
\hline$Z_{\text {AGE }}$ & $\delta_{1}$ & 0.001 & 0.131 & $-0.013^{* *}$ & -2.288 \\
\hline $\mathrm{Z}_{\mathrm{HHS}}$ & $\delta_{2}$ & 0.065 & 1.180 & -0.006 & -0.102 \\
\hline$Z_{E L}$ & $\delta_{3}$ & 0.049 & 0.515 & -0.072 & -1.236 \\
\hline$Z_{A E}$ & $\delta_{4}$ & -0.049 & -1.221 & 0.000 & 0.047 \\
\hline$Z_{\mathrm{PS}}$ & $\delta_{5}$ & 0.000 & -1.149 & -- & -- \\
\hline \multicolumn{6}{|c|}{ Variance parameters } \\
\hline $\begin{array}{l}\text { Sigma- } \\
\text { squared }\end{array}$ & $\sigma^{2}$ & $0.064^{* *}$ & 2.568 & $0.009^{* *}$ & 2.558 \\
\hline Gamma & $Y$ & $0.999^{* * *}$ & 16.577 & $0.999^{* * *}$ & 7.136 \\
\hline $\begin{array}{l}\text { Log } \\
\text { likelihood }\end{array}$ & -- & 0.160 & -- & 0.299 & -- \\
\hline LR test & -- & 10.682 & -- & 12.207 & -- \\
\hline \multicolumn{6}{|c|}{ TE estimates } \\
\hline \multicolumn{2}{|c|}{ Mean } & $46.75 \%$ & & $91.26 \%$ & \\
\hline \multicolumn{2}{|c|}{ Max } & $100.00 \%$ & & $99.83 \%$ & \\
\hline \multicolumn{2}{|c|}{ Min } & $22.00 \%$ & & $69.20 \%$ & \\
\hline \multicolumn{2}{|c|}{ SD } & 20.42 & & 7.77 & \\
\hline \multicolumn{2}{|c|}{ Skewness } & 1.40 & & -1.42 & \\
\hline
\end{tabular}

Table 3: Maximum-likelihood estimates of the SFPF and inefficiency function.

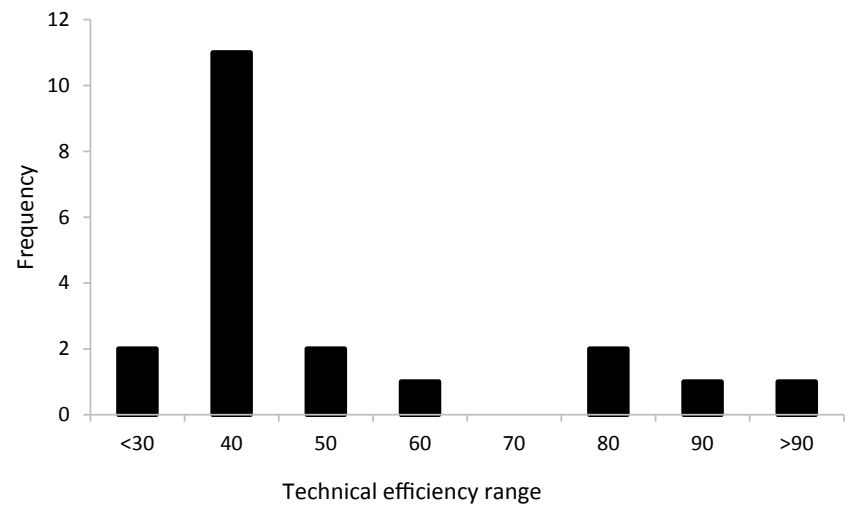

Figure 1: Distribution of technical efficiency estimates for Malawi farms.

had technical efficiency scores of less than $50 \%$, while $70 \%$ of farmers in China were producing at above $90 \%$ efficiency. Only $5 \%$ of Malawian farmers were above $90 \%$ technically efficient.

\section{Discussion}

Results of the Cobb Douglas model indicate that with a positive sign in most coefficients, ceteris paribus an increase in a particular input will result in an increase in yield. With respect to seed (fingerlings), manure and drugs the elasticity of output was not statistically significant. However, the results show that the elasticity of output with respect to feed was statistically significant, hence for a $10 \%$ increase in fish feed, 


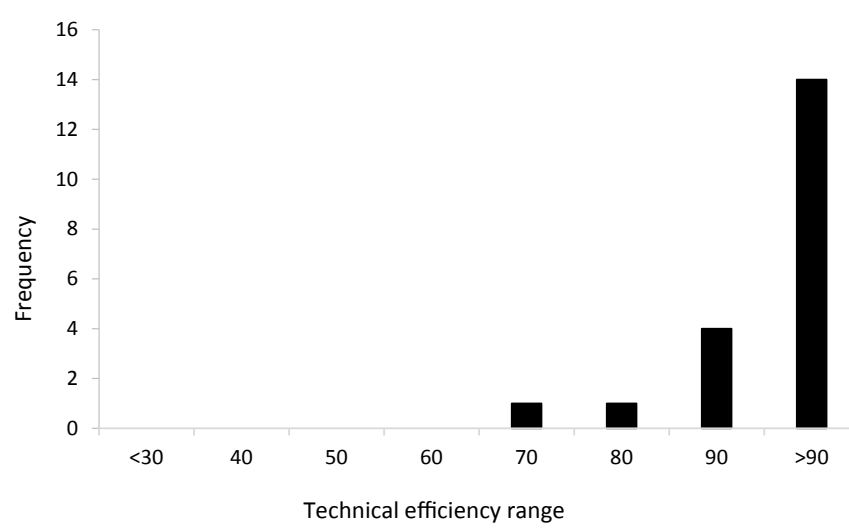

Figure 2: Distribution of technical efficiency estimates for China farms.

production is expected to increase by $14 \%$ in Malawi, and $4.34 \%$ in China farms. Apart from feed, coefficients of drugs and electricity for China farms had statistical significant effects, hence $10 \%$ increase in these inputs is expected to contribute an increased yield of 1.44 and $0.35 \%$ respectively. A marginal $10 \%$ increase in manure and drugs in the production of tilapia in Malawi, could result in a yield increase of 1.88 and $0.17 \%$ respectively. Furthermore, an insignificant change is expected with a $10 \%$ increase in seed $0.65 \%$ (Malawi) and $0.15 \%$ (China). This is in agreement with Akenbor and Ike [40] who found that technical efficiency was significantly and positively influenced by stocking rate in catfish farming in Edo, Nigeria. However, the results are in disagreement with Tung [51], who reported a negative relationship between stocking density and technical efficiency for shrimp in Vietnam. For an increase in labour, it is expected that production will decrease in Malawi by $0.49 \%$ which is in agreement with [34], and an insignificant increase of $0.0005 \%$ in China farms.

Just like Alam et al. [25] observes, age of farmers was a significant determinant of technical inefficiency for Chinese farms. However, it had significant positive influence on technical efficiency as was in Dey et al. study [22] and Zhang et al. study [52], conversely it had insignificant negative influence for Malawian farms, which was similar to earlier findings by [35] in a study on prawn farming in Vietnam. Household size which is credited to contribute to availability of farm labour had a non-significant but negative influence on inefficiency for Chinese farms, hence it positively influenced efficiency. Furthermore, the factor negatively influenced technical efficiency for tilapia farms in Malawi. Results of the present study further show that education coefficient has a positive sign, for Malawi, and negative for China. Since the factors were coded in descending order 5 (no education) and 1 (University education), the results signify a positive influence on efficiency for Malawian farmers, which was similar to findings by Tung [51] and Dey et al. [22]. Education can enhance production in that the higher a farmer goes with education, the better he becomes in assessment of the importance of new technologies, as well as the efficient use of inputs. Besides, education improves the managerial capacity of a farmer, which consequently leads to significantly higher efficiency. However, increased education will result in reduced technical efficiency for Chinese farmers, which is in agreement with findings by Chiang et al., Akenbor and Ike and Khan and Alam [34,40,53].

The coefficient of aquaculture experience though insignificant, positively influenced technical efficiency in Malawian farms which was also reported in earlier studies by Den et al., Tung, Kaliba and Engle $[35,51,54]$ but had negative influence on the technical efficiency of tilapia farms in China. With an average of 9.55 years of experience, any marginal year increase in experience could result in highly insignificant recession in efficiency for Chinese farmers, which was in agreement with $[34,53,52]$. For Malawi, pond size was found to have a positive but insignificant influence on technical efficiency. The result supports earlier findings by Tung, Penda et al., Huy, Alam and Murshed-e-Jahan, and Ogundari and Ojo [51,55-58].

\section{Conclusion and Recommendations}

In this study; "technical efficiency of tilapia production in Malawi and China", the study has revealed that most of the farmers in China operate at above $90 \%$ technical efficiency, while about $65 \%$ of Malawian farmers are technically inefficient, with an average technical efficiency of $47 \%$, hence have $53 \%$ room on average, within which they can improve. Thus, the farmers in Malawi have the potential to increase yield per hectare from the current average of $4152.60 \mathrm{~kg}$ to $8714.80 \mathrm{~kg}$. Malawi needs technology innovations in order to reduce this $53 \%$ yield gap, which can ideally be introduction or development of new strains of superior quality, enhanced use of all-male tilapia and improvement in both nursing and grow-out technologies. Just as it has been observed that very few farmers operate at above $90 \%$ efficiency, enhanced farmer to farmer contact i.e., full rollout of lead farmer initiative to enhance information sharing can help in motivating other farmers whose performance is low in order to improve the way they use resources in their tilapia farming operations. The significant positive constant coefficient of inefficiency function shows that there are inefficiency effects in tilapia production in Malawi, therefore there are possibilities for improving the performance as evidenced by the variations in the standard deviation range of efficiency scores from the mean technical efficiency. Finally, the highly statistical significant and positive sign of feed coefficient signifies that feed input is key to improved tilapia production in Malawi, so subsidised formulated feed has the potential to change the aquaculture production landscape. However, with education having positive influence on production elasticity, more aquaculture development programmes might yield tangible results if the target beneficiaries are people with formal education. For Chinese farms, the $9 \%$ average yield gap can be reduced by improving the resource-use efficiency of feed.

\section{Conflict of Interest}

The authors declare that they have no conflict of interest.

\section{References}

1. Malawi Government (2016) National Fisheries and Aquaculture Policy. (2nd edn). Lilongwe, Malawi.

2. FAO (2016) The State of World Fisheries and Aquaculture. Contributing to food security and nutrition for all. Rome. p: 200.

3. FAO (2015) Fisheries and aquaculture software. FishStatJ - Software for fishery statistical time series. FAO Fisheries and Aquaculture Department FAO, Rome.

4. Mussa R (2006) Technical efficiency of smallholder farmers in Southern Malawi: A study of adopters and non-adopters of integrated aquaculture agriculture. Department of Economics, Chancellor College-University of Malawi.

5. Chimatiro SK, Chirwa BB (2007) Analysis of feeds and fertilizers for sustainable aquaculture development in Malawi. In MR Hasan, T Hecht, SS De Silva and AGJ Tacon (eds). Study and analysis of feeds and fertilizers for sustainable aquaculture development. FAO Fisheries Technical Paper. No. 497. FAO, Rome, pp: 437-452.

6. Malawi Government (2006) Towards reliable, responsive and high-quality weather and climate services in Malawi.

7. Fare R, Grosskopf S, Lovell CAK (1985) The measurement of efficiency of production, Kluwer-Nijhoff Publishers. 
Citation: Phiri F, Yuan X (2018) Technical Efficiency of Tilapia Production in Malawi And China: Application of Stochastic Frontier Production Approach. J Aquac Res Development 9: 532. doi: 10.4172/2155-9546.1000532

8. Farrell JJ (1957) The measurement of productivity efficiency. J R Stat Soc Ser A 120: 253-290.

9. Coelli T, Rao DS, Battese GE (1998) An Introduction to Efficiency and Productivity Analysis, Kluver Academic Publishers, Norwell, MC.

10. Mires D (1995) The tilapias. In: Nash C.E. and Novotny A.J, (eds) World Aquatic Sciences (C8), Production of aquatic animals: Fishes. Elsevier Science, New York, USA. pp: 133-152

11. Gupta MV, Acosta BO (2004) A review of global tilapia farming practices. Retrieved on January 06, 2016, from Network of Aquaculture Centres in Asian-Pacific.

12. DeLong DP, Losordo TM, Rakocy JE (2009) Tank culture of Tilapia, Southern Regional Aquaculture Center Pub. SRAC-282: $4 p$.

13. Zhao J (2011) Tilapia germplasm in China: Chance and challenges.

14. Govender S (2009) Introduction to labour market economics, Management College of Southern Africa.

15. Lai Q, Yang Y (2004) Tilapia culture in Mainland China.

16. Yuan Y, Yuan Y, Dai Y, Gong Y (2017) Economic profitability of tilapia farming in China. Aquaculture International. Aquac Int 25: 1253-1264

17. Ahmed N, Young JA, Dey MM, Muir JF (2012) From production to consumption: a case study of tilapia marketing systems in Bangladesh. Aquac Int 20: 51-70.

18. Aigner DJ, Amemiya T, Porier DJ (1976) On the estimation of production frontiers: maximum likelihood estimation of the parameters of a discontinuous density function. J Econom 17: 377-396

19. Aigner DJ, Lovell CAK, Schimidt P (1977) Formulation and estimation of stochastic frontier production models. J Econom 6: 21-37.

20. Meeusen W, Van den Broeck J (1977) Efficiency estimation from CobbDouglas production function with composed errors. Int Econ Rev 8: 435-444.

21. Sharma KR, Leung PS (2000a) Technical efficiency of carp pond culture in south Asia: An application of a stochastic meta-production frontier model. Aquacu Econ Manag 4: 169-189.

22. Dey MM, Paraguas FJ, Bimbao GB, Regaspi PB (2000) Technical efficiency of tilapia grow-out pond operations in the Philippines. Aquacu Econ Manag 4: 33-47.

23. Dey MM, Paraguas FJ, Sricantuk N, Yuan X, Bhatta R, et al. (2005) Technical efficiency of freshwater pond polyculture production in selected Asian countries: estimation and implication. Aquacu Econ Manag 9: 39-63.

24. Singh K, Dey MM, Rabbani AG, Sudhakaran PO, Thapa G (2009) Technical efficiency of freshwater aquaculture and its determinants in Tripura, India. Agr Econ Res Rev 22: 185-195.

25. Alam F, Khan A, Huq A (2012) Technical efficiency in tilapia farming of Bangladesh: a stochastic frontier production approach. Aquac Int 20: 619-634.

26. Battese GE, Coelli TJ (1995) A model of technical inefficiency effects in a stochastic frontier production function for panel data. Emp Econ 20: 325-332.

27. Charnes A, Cooper WW, Rhodes E (1978) Measuring the efficiency of decision-making units. Eur J Oper Res 2: 429-444.

28. Kirkly JE, Squires D, Strand IE (1995) Assessing technical efficiency in commercial fisheries: the mid-Atlantic sea scallop fishery. Am J Agric Econ 77: 686-697.

29. Kirkly JE, Squires D, Strand IE (1998) Characterizing managerial skill and technical efficiency in fishery. J Prod Anal 9:145-160.

30. Jaforullah M, Devlin NJ (1996) Technical efficiency in the New Zealand dairy industry: a frontier production function approach. N Z Econ Paper. 30: 1-17.

31. Sharma KR, Leung PS (2000b) Technical efficiency of carp production in India: a stochastic frontier production function analysis. Aquac Res 31: 937-947.

32. Bimbao GB, Paraguas FJ, Dey MM, Eknath AE (2000) Socio-economics and production efficiency of tilapia hatchery operations in the Philippines. Aquacu Econ Manag 4: 47-61.

33. Irz X, Mckenzie V (2003) Profitability and technical efficiency of aquaculture systems in Pampanga, Philippines. Aquacu Econ Manag 7: 195-211.

34. Chiang FS, Sun CH, Yu MJ (2004) Technical efficiency analysis of milkfish (Chanos chanos) production in Taiwan - an application of the stochastic frontier production function. Aquaculture 23: 99-116.
35. Den TD, Ancev T, Harris M (2007) Technical efficiency of prawn farms in the Mekong delta, Vietnam, $51^{\text {st }}$ AARES Annual Conference, February 13-16, 2007; Australian Agricultural and Resource Economics Society, Queenstown, New Zealand.

36. Kareem RO, Dipeolu AO, Aromolaran AB, Akegbejo S (2008) Analysis of technical, allocative and economic efficiency of different pond systems in Ogun State, Nigeria. Afr J Agric Res 3: 246-254.

37. Ekunwe PA, Emokaro CO (2009) Technical efficiency of catfish farmers in Kaduna, Nigeria. J Appl Sci Res 5: 802-805

38. Bukenya JO, Hyuha TS, Molnar J, Twinamasiko J (2013) Efficiency of resource use among pond fish farmers in central Uganda: a Stochastic Frontier Production Function Approach. Aquac Econ Manag 17: 148-170.

39. Adeogun OA, Alimi T, Adeyemo R (2014) Comparative analysis of profitability and technical efficiency of fish farming using different rearing techniques in Nigeria. Asian J Agric Exten, Econ Sociol 3: 405-418.

40. Akenbor AS, Ike PC (2015) Analysis of technical efficiency of catfish farming in Edo State, Nigeria. J Bio Agric Healt 5: 2015.

41. Pitt MM, Lee MF (1981) Measurement and sources of technical inefficiency viewpoint in the Indonesian weaving industry. J Dev Econ 9: 43-64.

42. Kalirajan K (1981) An econometric analysis of yield variability in paddy production. Canadian Journal of Agricultural Economics 29: 283-294.

43. Battese GE, Coelli TJ, Colby TC (1989) Estimation of frontier production functions and the efficiencies of Indian farms using panel data from ICRISAT's village level studies. J Quant Econ 5: 327-348.

44. Kumbhakar SC, Ghosh S, McGuckin JT (1991) A generalized production frontier approach for estimating the determinants of inefficiency in US dairy farms. J Bus Econ Stat 9: 279-286.

45. Reifschneider D, Stevenson R (1991) Systematic departures from the frontier: a framework for the analysis of farm inefficiency. Int Eco Rev 32: 715-723.

46. Simar L, Wilson PW (2007) Estimation and inference in two-stage, semiparametric models of production processes. J Econom 136: 31-64.

47. Coelli TJ (1994) A guide to Frontier version 4.1: A computer programme for stochastic frontier production and cost function estimation. Department of Econometrics, University of New England, Armidale.

48. Sharma KR, Leung PS (1998) Technical efficiency of carp production in Nepal: an application of the stochastic frontier production function approach. Aqua Eco Mgmt 2: 129-140.

49. Battese GE, Coelli TJ (1993) A stochastic frontier production function incorporating a model for technical inefficiency effects. Working Papers in Econometrics and Applied Statistics No 69, Department of Econometrics. University of New England. Armidale.

50. Coelli TJ, Battese GE (1996) Identification of factors which influence the technical efficiency of Indian farmers. Aust J Agric Resour Econ 40: 103-128.

51. Tung PBV (2010) Technical efficiency of improved extensive shrimp farming in Ca mau province, Vietnam, MSc. thesis, University of Troms $\varnothing$, Norway \& Nha Trang University, Vietnam.

52. Zhang Z, Zhang Y, Li F, Yang H, Yuan Y, et al. (2016) Economic efficiency of small-scale tilapia farms in Guangxi, China. Aqua Eco and Mgmt pp 283-294.

53. Khan A, Alam F (2003) Technical efficiency of the hatchery operators in fish seed production farms in two selected areas OF Bangladesh. Banglav JAgric Econ pp: 55-70.

54. Kaliba AR, Engle CR (2006) Productive efficiency of catfish farms in Chicot County, Arkansas. Aqua Cul Mgmt, 10: 223-243.

55. Penda ST, Unaji GP, Odoenmenem U (2013) Profitability analysis of fish production from concrete pond system in Benue State, Nigeria. Int $\mathrm{J}$ Res Socl Sci 2: 2936-2943.

56. Huy DHX (2009) Technical efficiency analysis for commercial Black Tiger Prawn (Penaeus monodon) aquaculture farms in Nha Trang City, Vietnam, MSc. thesis, University of Troms $ø$, Norway \& Nha Trang University, Vietnam.

57. Alam MF, Murshed-e-Jahan K (2008) Resource allocation efficiency of the prawn carp farmers of Bangladesh. Aqua Eco Mgmt 12: 188-206.

58. Ogundari K, Ojo SO (2006) An examination of technical, allocative and Economic efficiency of small farmers: A case study of cassava farmers in Osun State, Nigeria. Journal of Cen Eur Agr 7: 423-432. 